\title{
The Psychological and Social Impacts of Curfew during the COVID-19 Outbreak in Kuwait: A Cross-Sectional Study
}

\author{
Ahmad Salman ${ }^{1,2,3, *(\mathbb{D})}$, Fatima Al-Ghadban ${ }^{4} \mathbb{D}$, Kennedy Ouma Sigodo ${ }^{5} \mathbb{D}$, Ayyoub K. Taher ${ }^{6}$ \\ and Sungsoo Chun 2,7 iD
}

check for updates

Citation: Salman, A.; Al-Ghadban, F.; Sigodo, K.O.; Taher, A.K.; Chun, S. The Psychological and Social Impacts of Curfew during the COVID-19

Outbreak in Kuwait: A

Cross-Sectional Study. Sustainability 2021, 13, 8464. https://doi.org/ $10.3390 /$ su13158464

Academic Editors: Marc A. Rosen and Serik Meirmanov

Received: 9 June 2021

Accepted: 20 July 2021

Published: 29 July 2021

Publisher's Note: MDPI stays neutral with regard to jurisdictional claims in published maps and institutional affiliations.

Copyright: (c) 2021 by the authors. Licensee MDPI, Basel, Switzerland. This article is an open access article distributed under the terms and conditions of the Creative Commons Attribution (CC BY) license (https:/ / creativecommons.org/licenses/by/ $4.0 /)$.
1 Ministry of Health, Safat 13001, Kuwait

2 Kuwait Public Policy Centre, General Secretariat of the Supreme Council for Planning and Development, Safat 13001, Kuwait; sungsoo.chun@undp.org

3 Physical Education Department, College of Education, Qatar University, Doha 2713, Qatar

4 College of Public Health and Human Sciences, Oregon State University, Corvallis, OR 97331, USA; alghadbf@oregonstate.edu

5 Department of Public Health, Glasgow Caledonian University London, London E1 6PX, UK; Kennedy.Sigodo@gcu.ac.uk

6 Environment and Life Sciences Research Center, Kuwait Institute for Scientific Research, Safat 13109, Kuwait; aktaher@kisr.edu.kw

7 The Institute of Global Health and Human Ecology, The American University in Cairo, AUC Avenue, New Cairo 11835, Egypt

* Correspondence: as1816@york.ac.uk

Abstract: The Coronavirus (COVID-19) pandemic in Kuwait led to a nationwide curfew between 22 March and August 2020. The purpose of this study was to evaluate the impact of the COVID-19 curfew during the pandemic on Kuwaiti citizens and residents. A cross-sectional survey was used to collect data from Kuwaiti residents over the age of 21 through an online questionnaire shared via social media, including WhatsApp and Facebook. Data collection occurred between 18 June and 15 July 2020. Data from 679 respondents (57.9\% females and 42.1\% males; $67.7 \%$ Kuwaiti nationals and $32.3 \%$ non-Kuwaiti nationals) were analyzed. Symptoms of depression were reported among $59.8 \%$ of females and $51.0 \%$ of males, and extremely severe depression among $20.4 \%$ of females and $13.6 \%$ of males. Approximately $42.0 \%$ of females and $37.8 \%$ of males were under psychological distress, with $15.1 \%$ of females and $9.1 \%$ of males experiencing severe or extremely severe psychological distress. Over a third of females (34.9\%) reported experiencing tensions or violent behaviors from family members, and $22.1 \%$ reported verbal or physical abuse. Among males, $26.4 \%$ reported experiencing tensions or violent behaviors, and $12.2 \%$ reported verbal or physical abuse. Extremely severe depression was associated with being female (2.00 times), aged 21-29 (4.56 times), experiencing tensions or violent behaviors from family members (4.56 times), being physically inactive (1.64 times), smoking cigarettes (3.02 times), and having poor or very poor quality of sleep (1.75 times). Severe or extremely severe psychological distress was associated with being female (3.09 times), aged 21-49 (3.68 times), having ill-health conditions or diseases (1.83 times), experiencing tension or violent behaviors from family members (3.56 times), smoking cigarettes (3.06 times), and having poor or very poor quality of sleep (2.20 times). Findings indicate that people living in Kuwait experienced negative psychological impacts, such as depression and psychological distress, attributable to the pandemic-related restrictions. Unpartnered females aged 21-49 are more mentally vulnerable than partnered males over the age of 50. Findings support an urgent need for targeted interventions to improve health behaviors and social support, including coping mechanisms specific to COVID-19 related stress, family counseling systems, and the provision of accessible and acceptable services using telehealth.

Keywords: COVID-19; psychological effect; depression; psychological distress; quality of sleep; wellbeing; Kuwait 


\section{Introduction}

After the Coronavirus disease (COVID-19) was confirmed at the end of December 2019 in Wuhan, China, COVID-19 began to spread rapidly to many countries [1]. By January 2020, the outbreak escalated to a public health emergency of international concern and was declared a pandemic in March 2020 [2]. In Kuwait, the first case of COVID-19 was confirmed on 24 February 2020. Since then, the State of Kuwait has faced profound public health challenges resulting from the direct impact of the pandemic, such as mortality and morbidity, and the impact of pandemic-related restrictions such as the curfew imposed between 22 March 2020 to 30 August 2020 that disrupted usual life patterns [3]. The COVID-19 curfew limited movements of all persons except individuals who required medical or emergency care and frontline workers with special permissions. During this period, most workplace organizations, public and private, as well as educational institutions transitioned into working from home virtually. COVID-19 has a wide-ranging adverse impact on the health behaviors of Kuwaiti citizens and residents [4].

The direct impacts of the pandemic and the strict restrictions such as social distancing and isolation increased the risk of mental health issues such as anxiety and depression [5]. Studies show evidence of the increased risks of depression and anxiety [6,7], stress [8], and other psychological problems [9] during the pandemic. The association between psychological outcomes and COVID-19 are linked to disruptions in the usual ways of living, working, and learning [8,9]. Apart from these disruptions, the pandemic induced panic and fear among people, whether fear of getting infected or losing a family member, fear of losing jobs and financial stability, or feeling lonely and isolated [10]. Uncertainties about the future due to the prevailing conditions further intensify the emotional difficulties caused by family stress, job losses, and increased physical and verbal abuse observed in some countries [11]. Considering the devastating current and long-term impact of COVID-19 on mental health and wellbeing, governments, healthcare systems, educational institutions, organizations, and non-governmental organizations are looking into interventions to mitigate the looming mental health crisis.

People react to public health emergencies such as the COVID-19 pandemic in both adaptive and maladaptive ways. According to Brailovskaia and Margraf, how people react determines the impact of the pandemic on their health [12]. Those who react in adaptive ways tend to acquire a good knowledge of the modes of disease transmission and signs and symptoms of the virus [12]. This group of people attempt to maintain their daily routines and, when possible, adapt to accommodate the prevailing life conditions. On the contrary, a maladaptive reaction to the pandemic is linked to an increased psychological burden due to increased uncertainties and anxiety resulting from the curfew and new living conditions. Mass media and social media have been implicated in both reactions [13,14].

Individual reactions to a disease threat are products of a wide range of factors. For instance, the World Health Organization (WHO) referred to the infodemic, defined as "too much information including false or misleading information in digital and physical environments during a disease outbreak," that was identified as a significant contributor to the confusion, risky health behaviors, and mental health problems that people faced during the pandemic [15]. Therefore, media coverage may cause an under or overestimation of disease risk or severity with probable severe health impacts [16]. On the other hand, accurate information allows individuals to obtain sufficient knowledge to safeguard their health and wellbeing during the pandemic [17].

According to the Health Belief Model [18], the perceived severity and susceptibility explain how individuals' beliefs predict their response to a disease. Depending on how much an individual feels susceptible or likely to suffer significant harm from an illness, one may adopt or disregard health-protecting behaviors $[14,19]$. Petrie and Weinman found that the perception of illness influenced individuals' emotional response to a disease threat, coping behaviors, and adherence to protective and preventive measures [20]. For instance, Kim et al. found that individuals who perceived themselves as at low risk of contracting Middle East Respiratory Syndrome (MERS) did not trust the government's ability to control 
the disease and were dismissive of measures to prevent the disease [21]. Other constructs within the Health Belief Model are the perceived benefits, perceived barriers, and selfefficacy [22]. This theoretical framework informs the rationale for measuring Kuwaiti residents' perceptions of COVID-19 to elucidate the factors influencing changes in their behaviors during the pandemic and consequent psychological and social impacts.

This study is a response to the WHO's and the United Nations (UN)'s recommendations to assess the impacts of the COVID-19 pandemic and related restrictions on individuals' mental health, including conditions such as depression, stress, anxiety, and psychological distress [23]. In particular, UN agencies encourage each country to investigate the health and social impacts of COVID-19 and design relevant interventions [24]. Therefore, this research aimed to evaluate the impact of the COVID-19 pandemic on Kuwaiti citizens and residents using the following objectives:

- Measuring residents' perceptions related to the COVID-19 pandemic.

- Assessing residents' mental health changes before and during the COVID-19 curfew.

- Describing the changes in health behaviors from before and during the COVID-19 curfew.

- Identifying risks related to negative psychological impacts of the COVID-19 curfew.

\section{Materials and Methods}

\subsection{Survey Method and Target Population}

The study employed a cross-sectional study design and survey method to collect data. The survey utilized an online, structured questionnaire distributed using social media, including WhatsApp and Facebook, between 19 June and 15 July 2020. The target population included Kuwaiti citizens and residents, 21 years and older, who live in the State of Kuwait. A convenience sample of 679 respondents completed the survey.

\subsection{Questionnaire Design and Tools}

The questionnaire was divided into sections that focused on measuring perceptions of COVID-19 by contextualizing the items such as perceived susceptibility, severity, barriers, self-efficacy, and cues to action using a tool validated in previous research [25]. Mental health was measured using the validated measure, Depression, Anxiety, and Stress Scale (DASS9) [26], which measures depression, anxiety, stress, and general psychological distress. Demographic information including age, gender, nationality, marital status, education level, and current health condition, which included diseases and illnesses such as high blood pressure, diabetes, and cardiovascular disease were self-reported by participants. Relationship dynamics were assessed by comparing them before and during the COVID-19 curfew. Consumption of sweets and snacks was measured by assessing preand during COVID-19 curfew with responses based on a 5-item Likert scale ranging from 'I eat much more' to 'I eat much less' compared to pre-pandemic times. Physical activity and exercise behaviors were measured using the validated International Physical Activity Questionnaire: Short Form (IPAQ-SF) [27].

\subsection{Research Ethics}

The Research Ethics Review Committee of the Kuwait Ministry of Health approved this research study on 8 June 2020 (\# 1487) and adhered to the American Association for Public Opinion Research (AAPOR) Code of Professional Ethics and Practices [28].

\subsection{Method of Analysis}

Analytical methods were applied using IBM Statistical Package and Services Solutions (SPSS) software version 25 (IBM Corp, Armonk, New York, NY, USA) and assessed at a $p$-value $<0.05$ for statistical significance. Descriptive statistics were conducted to describe sample characteristics and variables related to working conditions at home and health conditions. Cross tabs chi-square test and independent-samples $t$-test were conducted to identify gender differences in variables related to perceptions of COVID-19, mental 
health, and family relationships. Pearson's correlation coefficient analysis was performed to identify intercorrelation between dependent and independent variables. Binary logistic regression analysis was conducted to calculate the odds ratios for predicting mental health variables, including depression, anxiety, stress, and psychological distress. The following variables were dichotomized: gender, age, nationality, marital status, education, house type, working at home, illness or health condition, living in a household with an individual(s) with disabilities, tension with family members, violence and abuse from family members, food consumption, and hours and quality of sleep. With guidance on the classifications of mental health from previous research [26], the dependent variables were classified according to the following cut-offs for each variable: depression: normal, mild, moderate, and extremely severe; anxiety: normal, moderate, severe, and extremely severe; stress: normal, moderate, severe, and extremely severe; and psychological distress: normal, moderate, severe, and extremely severe. For binary logistic regression analyses, dependent variables were dichotomized into the following: depression: normal vs. depressed, normal vs. extremely severe depression; anxiety: normal vs. anxiety, normal vs. severe/extremely severe anxiety; stress: normal vs. stress, normal vs. severe/extremely severe stress; and psychological distress: normal vs. psychological distress, normal vs. severe/extremely severe psychological distress. Binary logistic analyses were conducted for each dependent variable with each independent variable. Finally, binary logistic multi-regression analysis was performed using the Forward Stepwise Wald method for predicting the levels of depression, anxiety, stress, and psychological distress.

\section{Results}

\subsection{General Characteristics}

The general characteristics of survey respondents are described in Table 1.

Table 1. Characteristics of the respondents $(n=679)$.

\begin{tabular}{cc}
\hline Variables & $\%$ \\
\hline Gender & 57.9 \\
Female & 42.1 \\
Male & \\
Age & 28.7 \\
$21 \sim 29$ & 29.3 \\
$30 \sim 39$ & 23.0 \\
$40 \sim 49$ & 15.2 \\
$50 \sim 59$ & 3.8 \\
60 and above & \\
Nationality & 67.7 \\
Kuwaiti & 32.3 \\
Non-Kuwaiti & \\
Marital status & 63.8 \\
Married & 29.7 \\
Single (never married) & 6.5 \\
Divorced/spouse deceased & \\
Education & 13.3 \\
than primary school & 16.5 \\
Diploma & 47.6 \\
College/University & 22.7 \\
Postgraduate &
\end{tabular}

\subsection{Working Conditions at Home}

During the COVID-19 curfew period, $64.5 \%$ of respondents worked from home as jobholders, and $63.9 \%$ were salaried employees. Approximately $63.4 \%$ of the respondents reported that time and effort spent on housework had increased during the COVID-19 outbreak (Table 2). 
Table 2. Working conditions at home $(n=679)$.

\begin{tabular}{cc}
\hline Variables & $\%$ \\
\hline Employment type & \\
Salaried employee & 63.9 \\
Retired & 8.2 \\
Unemployed & 6.0 \\
Business Owner & 5.0 \\
Student & 13.1 \\
Homemaker & 3.7 \\
Do you work for a job at home, even under Curfew (for & \\
students: are you continuing to study) during the & \\
COVID-19 outbreak? & 64.5 \\
No & 35.5 \\
Yes & \\
How much time and effort did you spend on housework & 10.9 \\
during the COVID-19 outbreak? & 25.8 \\
Rather reduced & 37.0 \\
Same as usual & 26.4 \\
Slightly increased &
\end{tabular}

\subsection{Health Conditions}

Approximately $33.1 \%$ of the respondents reported having existing medical conditions, of which high blood pressure was the highest at $11.5 \%$, followed by diabetes $(10.5 \%)$, chronic bronchitis $(5.4 \%)$, and cardiovascular diseases (3.2\%), respectively (Table 3). Moreover, $2.2 \%$ of respondents had been infected with coronavirus, and $50.4 \%$ of respondents knew individuals with confirmed infections within their immediate social environment.

Table 3. Health conditions of the respondents $(n=679)$.

\begin{tabular}{cc}
\hline Variables & $\%$ \\
\hline Do you have any conditions or diseases? (selected all & \\
that apply) & 11.5 \\
High blood pressure & 10.5 \\
Diabetes & 3.8 \\
Cardiovascular disease & 5.4 \\
Chronic bronchitis & 3.2 \\
Hereditary conditions & 1.5 \\
Mental illness & 0.9 \\
Cancer & 1.2 \\
Physical disability & 66.9 \\
None of the diseases & \\
coronavirus? & \\
Are you, or have you been, infected with the novel & 2.2 \\
Yes, tested and the result was positive & 2.2 \\
Yes, suspected but not confirmed by a test & 8.1 \\
No, tested and the result was negative & 72.9 \\
$\quad$ No & 14.6 \\
Don't know & \\
Do you know people in your immediate social & \\
environment who are or have been infected with the & 50.4 \\
novel coronavirus? & 3.4 \\
Yes, confirmed & 4.3 \\
Yes, suspected but not confirmed by a test & 36.4 \\
No, tested and the result was negative & 5.4 \\
No & \\
\hline
\end{tabular}




\subsection{Perception of COVID-19}

Table 4 and Figure 1 display gender differences in attitudes and perceptions related to the COVID-19 pandemic. More males perceived themselves to be risk-takers than females $(8.4 \%$ vs. $3.8 \%)$. Females' perceived severity of COVID-19 exceeded males' perceived severity.

Table 4. Gender differences in attitudes and perceptions related to the COVID-19 pandemic $(n=679)$.

\begin{tabular}{|c|c|c|c|}
\hline \multirow{2}{*}{ Variables } & Female $(n=393)$ & Male $(n=286)$ & \multirow{2}{*}{$\begin{array}{l}\text { x2-or } \mathrm{t}-\text {, and } \\
(p \text {-Value })\end{array}$} \\
\hline & \multicolumn{2}{|c|}{$\%$, Mean (SD) } & \\
\hline \multicolumn{4}{|l|}{ Do you consider yourself to be? } \\
\hline Risk Averse & 66.9 & 67.5 & \\
\hline Risk Takers & 3.8 & 8.4 & $7.651(0.022)$ \\
\hline Neutral & 29.3 & 24.1 & \\
\hline $\begin{array}{l}\text { Do you consider yourself adapting the right behaviors } \\
\text { and measurements to prevent the infection? }\end{array}$ & & & \\
\hline (Mal adaptation (1)-(2)-(3)-(4)-(5) Adaptation) & $4.45(0.89)$ & $4.36(1.00)$ & $1.225(0.221)$ \\
\hline $\begin{array}{l}\text { If I'm infected with coronavirus, it will come with } \\
\text { (My carelessness (1)-(2)-(3)-(4)-(5) Carelessness from } \\
\text { other community people) }\end{array}$ & $3.84(1.44)$ & $3.40(1.61)$ & $3.774(0.000)$ \\
\hline Perceived susceptibility ${ }^{1}$ & $3.30(1.18)$ & $3.40(1.00)$ & $-1.136(0.256)$ \\
\hline Perceived severity ${ }^{1}$ & $3.91(0.82)$ & $3.65(0.96)$ & $3.795(0.000)$ \\
\hline Perceived barriers $^{1}$ & $2.48(0.91)$ & $2.73(0.91)$ & $-3.666(0.000)$ \\
\hline Perceived self-efficacy ${ }^{1}$ & $3.91(0.83)$ & $3.92(0.78)$ & $-0.212(0.832)$ \\
\hline $\begin{array}{l}\mathrm{TV} \text {, radio, SMS, and Internet information about the } \\
\text { disease have been helpful }{ }^{1}\end{array}$ & $4.12(1.14)$ & $4.15(1.05)$ & $-0.389(0.698)$ \\
\hline $\begin{array}{l}\text { Is the news on Social Media and the Internet and TV } \\
\text { induce fear and feeling of threat? }\end{array}$ & $3.82(1.09)$ & $3.88(1.09)$ & $-0.656(0.512)$ \\
\hline
\end{tabular}

${ }^{1}$ Strongly disagree (1)-(2)-(3)-(4)-(5) Strongly agree.

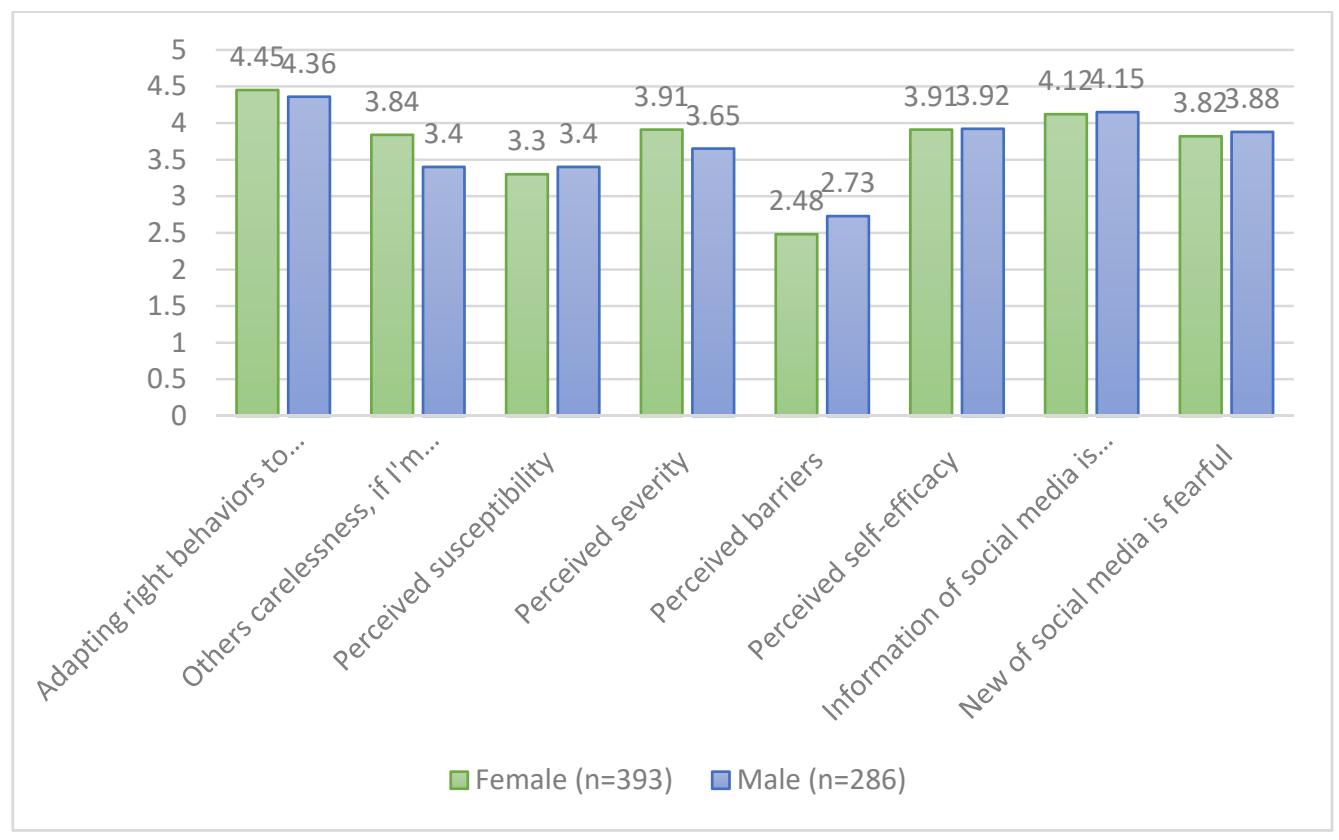

Figure 1. Attitudes and perception on COVID-19 pandemic.

Both males and females perceived themselves as highly adapting the right behaviors and measures to prevent infection. Still, males cited more barriers to adhering to the infection prevention measures than females. Both genders considered that "TV, radio, SMS, and internet information about the disease" was beneficial, and "the news on Social 
Media and the Internet and TV" significantly induced fear and feelings of threat related to the virus.

\subsection{Mental Health}

Table 5 shows gender differences in mental health status. More females report having mental health problems than males in parameters such as depression (59.8\% vs. $51.0 \%)$, anxiety $(14.5 \%$ vs. $8.7 \%)$, stress (18.3\% vs. $14.7 \%)$, and general psychological distress (42.0\% vs. $37.8 \%)$. However, only symptoms of depression were statistically significant $(p<0.05)$ between genders. Approximately $20.4 \%$ of females and $13.6 \%$ of males report experiencing extremely severe depression, and $15.1 \%$ of females and $9.1 \%$ of males report severe or extremely severe psychological distress. Moreover, $9.4 \%$ of females and $7.3 \%$ of males report being under severe or extremely severe stress. Additionally, $6.6 \%$ of females and $4.1 \%$ of males report experiencing severe or extremely severe anxiety.

Table 5. Gender differences of depression, anxiety, stress, and general psychological distress.

\begin{tabular}{|c|c|c|c|c|}
\hline \multirow{2}{*}{ Mental Health } & Total $(n=679)$ & Female $(n=393)$ & Male $(n=286)$ & \multirow{2}{*}{$x 2$-and ( $p$-Value) } \\
\hline & & $\%$ & & \\
\hline \multicolumn{5}{|l|}{ Depression } \\
\hline Normal & 43.9 & 40.2 & 49.0 & \\
\hline Mild & 19.9 & 21.6 & 17.5 & $8.980(0.030)$ \\
\hline Moderate & 18.7 & 17.8 & 19.9 & \\
\hline $\begin{array}{c}\text { Extremely severe } \\
\text { Anxiety }\end{array}$ & 17.5 & 20.4 & 13.6 & \\
\hline Normal & 87.9 & 85.5 & 91.3 & \\
\hline Moderate & 6.5 & 7.9 & 4.5 & $5.961(0.114)$ \\
\hline Severe & 2.9 & 3.8 & 1.7 & \\
\hline $\begin{array}{c}\text { Extremely severe } \\
\text { Stress }\end{array}$ & 2.7 & 2.8 & 2.4 & \\
\hline Normal & 83.2 & 81.7 & 85.3 & \\
\hline Moderate & 8.2 & 8.9 & 7.3 & $1.907(0.592)$ \\
\hline Severe & 5.3 & 6.1 & 4.2 & \\
\hline $\begin{array}{c}\text { Extremely severe } \\
\text { General } \\
\text { psychological } \\
\text { distress }\end{array}$ & 3.2 & 3.3 & 3.1 & \\
\hline Normal & 62.3 & 58.0 & 68.2 & \\
\hline Mild & 14.1 & 15.5 & 12.2 & \\
\hline Moderate & 11.0 & 11.5 & 10.5 & $8.876(0.064)$ \\
\hline Severe & 7.4 & 8.7 & 4.9 & \\
\hline Extremely severe & 5.4 & 6.4 & 4.2 & \\
\hline
\end{tabular}

\subsection{Family Relationship}

Table 6 explains the relationship dynamics with family members during the COVID-19 outbreak. Approximately $34.9 \%$ of female respondents reported that tensions or violent behaviors had increased in their relationships with other family members (husband/wife, parents, children) during the COVID-19 pandemic, while $26.4 \%$ of males reported an increase in tensions and violent behaviors. Females experience significantly more abuse, such as verbal or physical abuse, compared to males $(22.1 \%$ vs. $12.2 \%, p<0.01)$. The respondents cited fear about the future prospects $(36.8 \%)$, physical proximity $(26.5 \%)$, financial anxieties (25.3\%), and lack of common interest and/or hobbies $(20.6 \%)$ as the variables affecting their and family members' mental wellbeing, leading to tensions or even violent behaviors in their relationship during the COVID-19 outbreak. Among these variables, increased household work (23.4 vs. $11.5, p<0.001)$ and lack of common interest and/or hobbies $(23.7 \%$ vs. $16.4, p<0.05)$ were significantly cited by more females than males. 
Table 6. Relationship dynamics under the COVID-19 outbreak.

\begin{tabular}{|c|c|c|c|c|}
\hline \multirow{2}{*}{ Health Behaviors } & Total $(n=679)$ & Female $(n=393)$ & Male $(n=286)$ & \multirow{2}{*}{$\chi^{2}$-and ( $p$-Value) } \\
\hline & \multicolumn{3}{|c|}{$\%$} & \\
\hline \multicolumn{5}{|l|}{$\begin{array}{l}\text { Have tensions or even violent behavior increased in the } \\
\text { relationships with any of your family members } \\
\text { (husband/wife, parents, children) compared to before } \\
\text { the outbreak of COVID-19? }\end{array}$} \\
\hline Yes & 31.3 & 34.9 & 26.4 & \\
\hline No & 65.4 & 62.3 & 68.7 & $5.717(0.057)$ \\
\hline I refuse to answer & 3.2 & 2.8 & 3.9 & \\
\hline \multicolumn{5}{|c|}{$\begin{array}{l}\text { Have these tensions in your relationships with any of } \\
\text { your family members (husband/ wife, parents, children) } \\
\text { resulted in physical or verbal abuse? }\end{array}$} \\
\hline Verbal abuse & 14.1 & 17.8 & 9.1 & \\
\hline Physical abuse & 0.9 & 0.5 & 1.4 & \\
\hline Verbal and physical abuse & 2.9 & 3.8 & 1.7 & $14.888(0.005)$ \\
\hline No & 78.5 & 74.3 & 84.3 & \\
\hline I refuse to answer & 3.5 & 3.6 & 3.5 & \\
\hline \multicolumn{5}{|l|}{$\begin{array}{l}\text { In your view, what are the factors affecting the mental } \\
\text { wellbeing of yourself and any of your family members, } \\
\text { leading to tensions or even violent acts in the } \\
\text { relationship during the COVID-19 outbreak? (Please } \\
\text { select all that apply) }\end{array}$} \\
\hline Physical proximity & 26.5 & 26.7 & 26.2 & $0.021(0.930)$ \\
\hline Increased demands at the job & 10.3 & 11.2 & 9.1 & $0.793(0.443)$ \\
\hline Increased household work & 18.4 & 23.4 & 11.5 & $15.531(0.000)$ \\
\hline Increased tasks to guide children's learning & 15.9 & 18.1 & 12.9 & $3.256(0.089)$ \\
\hline Financial anxieties & 25.3 & 24.4 & 26.6 & $0.403(0.533)$ \\
\hline Fear about the future prospects & 36.8 & 34.4 & 40.2 & $2.442(0.126)$ \\
\hline Lack of common interest and/or hobbies & 20.6 & 23.7 & 16.4 & $5.288(0.022)$ \\
\hline Lack of physical exercise and sport & 17.1 & 15.0 & 19.9 & $2.826(0.099)$ \\
\hline Lack of sleep and rest & 21.2 & 23.2 & 18.5 & $2.118(0.155)$ \\
\hline Increased negative health symptoms & 11.0 & 12.5 & 9.1 & $1.922(0.175)$ \\
\hline Others & 25.3 & 24.7 & 26.2 & $0.208(0.656)$ \\
\hline
\end{tabular}

\subsection{Correlations between Mental Health and Health Behaviors}

Mental health was highly correlated with health behaviors such as physical activity, smoking cigarettes, and the quality of sleep (Table 7). Physical activity significantly reduced stress; the more days of being active per week, the lower the stress score $(p<0.05)$. The daily frequency of smoking was positively correlated with depression scores $(p<0.05)$. The quality of sleep was inversely correlated with all mental health parameters, including depression $(p<0.01)$, anxiety $(p<0.01)$, stress $(p<0.01)$, and psychological distress $(p<0.01)$; the better quality of sleep, the lower the scores of all mental health parameters.

Table 7. Correlations between mental health and health behaviors.

\begin{tabular}{ccccc}
\hline & Depression & Anxiety & Stress & $\begin{array}{c}\text { General Psychological } \\
\text { Distress }\end{array}$ \\
\hline Days of physical activities & -0.061 & -0.037 & $-0.085^{*}$ & -0.074 \\
Daily amount of smoking cigarette & $0.084^{*}$ & 0.013 & 0.020 & 0.049 \\
Daily amount of smoking shisha & 0.041 & 0.033 & 0.059 & 0.054 \\
Sleep hours & 0.047 & 0.013 & 0.014 & 0.031 \\
Quality of sleep & $-0.139 * *$ & $-0.181^{* *}$ & $0.158^{* *}$ & $-0.194^{* *}$ \\
\hline * & & & &
\end{tabular}

${ }^{*}: p<0.05 ;{ }^{* *}: p<0.01$.

\subsection{Predictors of Mental Health Status}

\subsubsection{Predictor Variables Associated with Depression and Extremely Severe Depression}

Table 8 shows the final prediction models for both depression and extremely severe depression controlled by sociodemographic factors and health behaviors. Gender was a factor in predicting extremely severe depression. Females were twice as likely to have extremely severe depression than males, but there was no difference between genders in the likelihood of depression. Age was a significant predictor of both depression and 
extremely severe depression. Individuals aged 21-49 were 2.18 times more likely to have depression and 4.56 times more likely to have extremely severe depression than persons aged 50 and above. In addition, individuals who report experiencing increased tensions or violent behaviors within the family were 2.07 times more likely to report symptoms of depression and were 2.88 times more likely to have extremely severe depression than those who had not experienced increased tensions or violent behaviors. People who reported eating more 'sweets and snacks' than before the COVID-19 outbreak were 1.52 times more likely to report symptoms of depression than those who ate the same or lesser. Exercise was a predictor of extremely severe depression. Individuals who were not physically active for at least $30 \mathrm{~min}$ per week were 1.64 times more to report symptoms of extremely severe depression than those who were physically active for $30 \mathrm{~min}$ or more per week. Smoking cigarettes was a good indicator for predicting both depression and extremely severe depression. Smokers were 1.63 times more likely to be under depression and 3.02 times more likely to have extremely severe depression than non-smokers. Both the hours and quality of sleep predicted depression and extremely severe depression, respectively. Those who slept less than $8 \mathrm{~h}$ or more than $9 \mathrm{~h}$, including naps per day, were 1.55 times more likely to report symptoms of depression than those who had 8-9 h of sleep per day. Individuals who reported 'poor' or 'very poor' sleep quality were 1.75 times more likely to report having symptoms of extremely severe depression than those who reported 'good' or 'very good' sleep quality.

Table 8. Predictor variables related to depression.

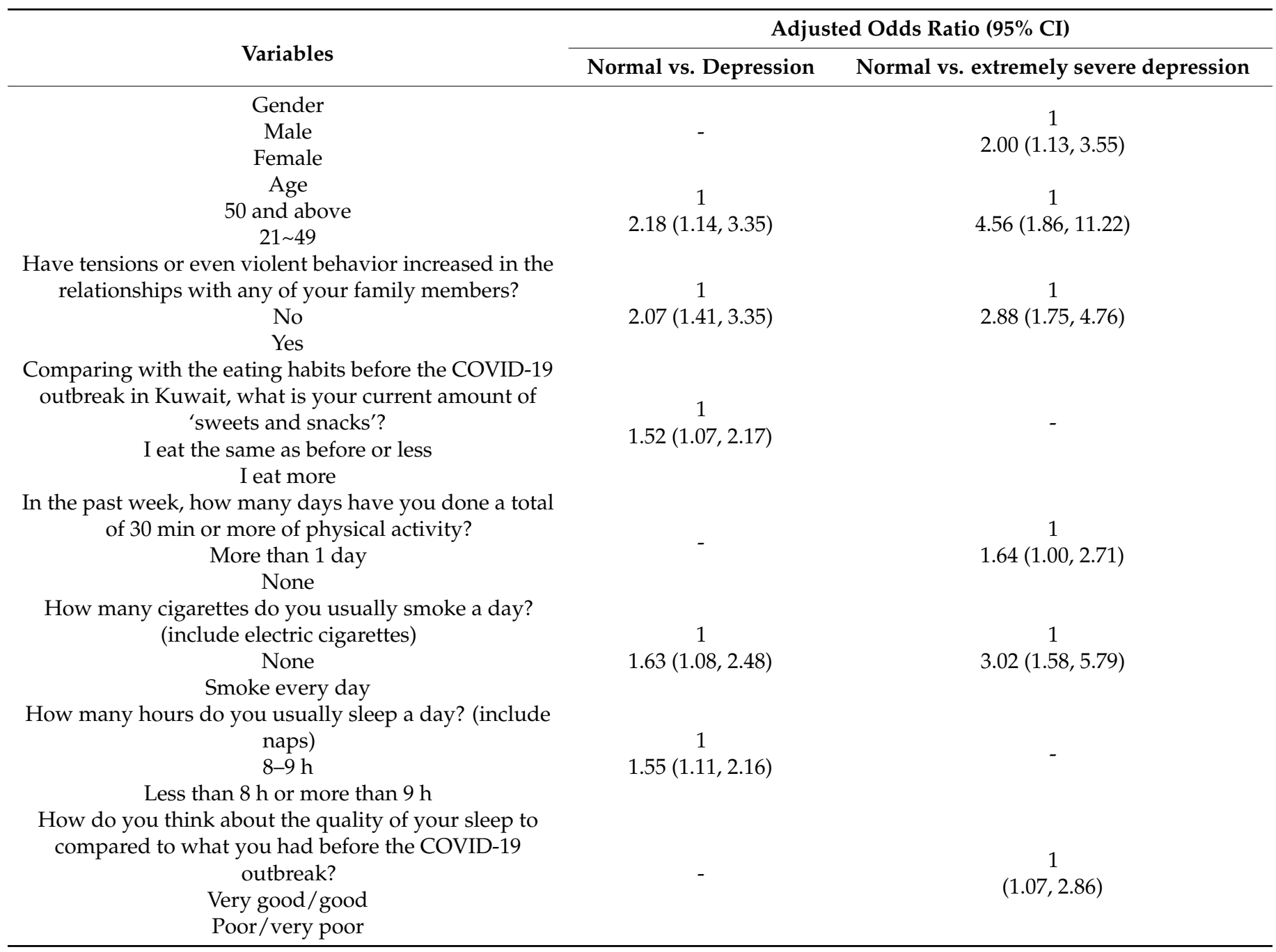




\subsubsection{Predicting Variables to Depression and Extremely Severe Depression}

Table 9 shows the final models for predicting both anxiety and severe or extremely severe anxiety controlled by sociodemographic factors and behaviors. Compared to those who were married, individuals who were single, divorced, or widowed were 2.54 times more likely to have severe or extremely severe anxiety. Those with chronic ill-health conditions or diseases were 2.11 times more likely to be under severe or extremely severe anxiety than those without chronic ill-health conditions. Individuals who had increased tensions or violent behaviors with family members during the COVID-19 outbreak were 2.52 times more likely to report symptoms of anxiety and 3.24 times more likely to report symptoms of severe or extremely severe anxiety than those who had not. Those who reported 'poor' or 'very poor' sleep quality were 2.07 times more likely to report symptoms of anxiety and 2.79 times more likely to report symptoms of severe or extremely severe anxiety than those who reported 'good' and 'very good' sleep quality.

Table 9. Predictor variables related to anxiety.

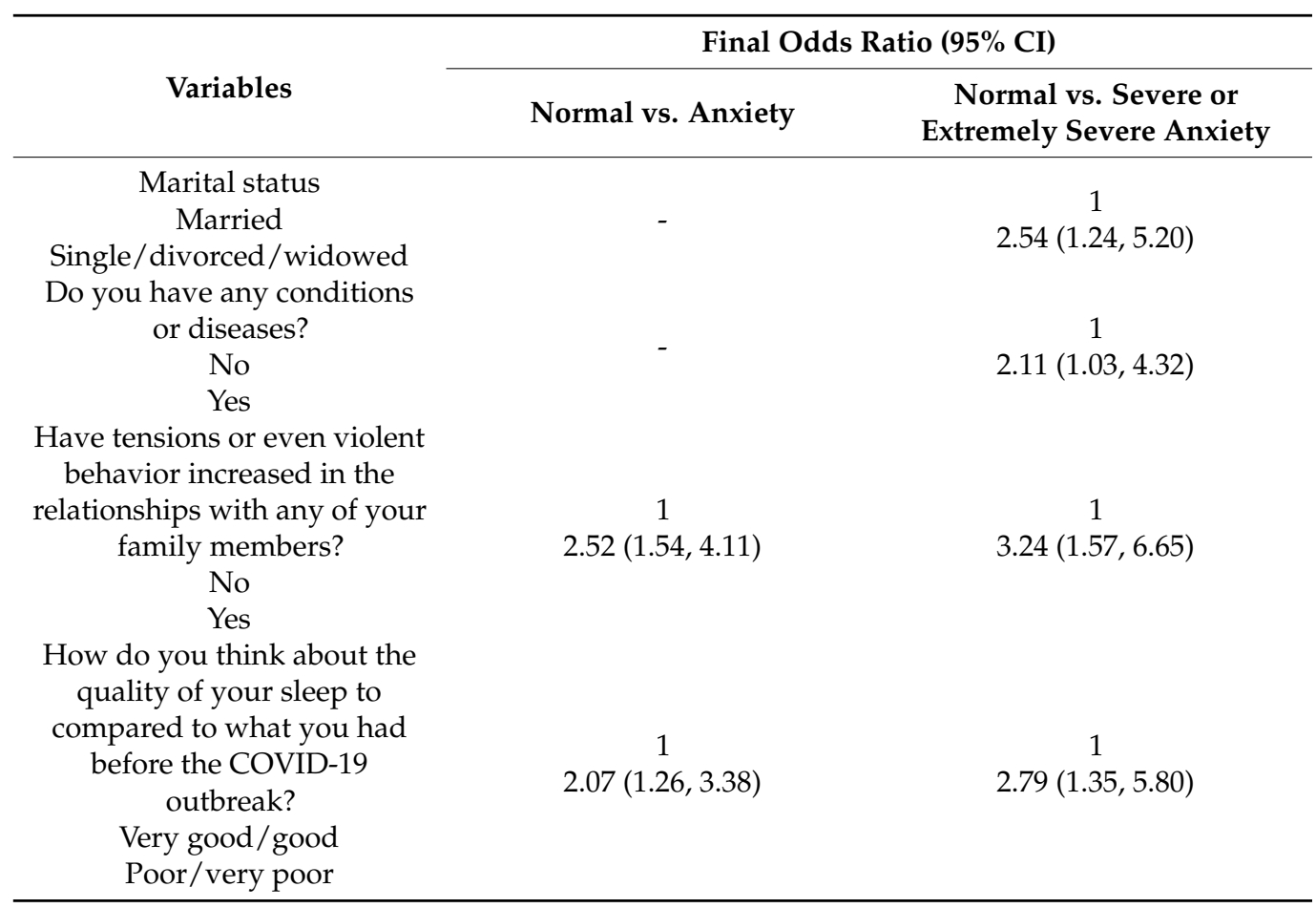

\subsubsection{Predicting Variables to Stress and Severe or Extremely Severe Stress}

Table 10 is the final model for predicting both stress and severe or extremely severe stress controlled by sociodemographic and other behaviors. Marital status, tensions with family members, and sleep quality are significant predictors of both stress and severe or extremely severe stress, while smoking cigarettes predicted stress only. Single, divorced, or widowed individuals are 1.63 times more likely to report being under stress and 1.83 times more likely to report severe or extremely severe stress than married individuals. The people who experienced increased tensions or violent behaviors with family members during the COVID-19 outbreak are 3.07 times more likely to report being under stress and 3.52 times more likely to report severe or extremely severe stress than those who do not experience tensions or violent behaviors. Individuals who report 'poor' or 'very poor' sleep quality are 1.94 times more likely to report symptoms of stress and 1.99 times more likely to report being under severe or extremely severe stress than those who report 'good' and 'very good' sleep quality. Smokers are 1.70 times more likely to report symptoms of stress than non-smokers. 
Table 10. Predicting variables to stress.

\begin{tabular}{ccc} 
& \multicolumn{2}{c}{ Final Odds Ratio (95\% CI) } \\
\cline { 2 - 3 } Variables & Normal vs. Stress & $\begin{array}{c}\text { Normal vs. Severe or Extremely } \\
\text { Severe Stress }\end{array}$ \\
\hline $\begin{array}{c}\text { Marital status } \\
\text { Married }\end{array}$ & 1 & 1 \\
$\begin{array}{c}\text { Single/divorced/widowed } \\
\text { Have tensions or even violent } \\
\text { behavior increased in the } \\
\text { relationships with any of your } \\
\text { family members? } \\
\text { No } \\
\text { Yes }\end{array}$ & $1.63(1.05,2.54)$ & $1.83(1.01,3.29)$ \\
$\begin{array}{c}\text { How many cigarettes do you } \\
\text { usually smoke a day? (include } \\
\text { electric cigarettes) } \\
\text { None }\end{array}$ & 1 & 1 \\
$\begin{array}{c}\text { Smoke every day } \\
\text { How do you think about the }\end{array}$ & 1 & \\
quality of your sleep to compared \\
to what you had before the \\
COVID-19 outbreak? \\
$\begin{array}{l}\text { Very good/good } \\
\text { Poor/very poor }\end{array}$
\end{tabular}

3.8.4. Predicting Variables to Psychological Distress and Severe or Extremely Severe Psychological Distress

Table 11 is the final model for predicting both psychological distress and severe or extremely severe psychological distress controlled by sociodemographic and other behaviors. Females were 3.09 times more likely to report severe or extremely severe psychological distress than males. Individuals aged 21-49 were 2.43 times more likely to have psychological distress and 3.68 times more to experience severe or extremely severe psychological distress than those aged 50 and above. Individuals with chronic ill-health conditions or diseases were 1.55 times more likely to report psychological distress and 1.83 times more likely to report severe or extremely severe psychological distress than those without chronic conditions. People who experienced increased tensions or violent behaviors with family members during the COVID-19 outbreak were 1.68 times more likely to report psychological distress and 3.56 times more likely to report being under severe or extremely severe psychological distress than those who did not experience tensions or violent behaviors. Individuals who experienced verbal or physical abuse from family members were 1.66 times more likely to report psychological distress than individuals who did not experience abuse. Individuals who ate more sweets and snacks during the pandemic than before the COVID-19 outbreak were 1.46 times more likely to report psychological distress than those who ate less than before the pandemic. Smokers were 3.06 times more likely to report severe or extremely severe psychological distress than non-smokers. Individuals who reported having 'poor' or 'very poor' sleep quality were 1.61 times more likely to report psychological distress and 2.20 times more likely to report being under severe or extremely severe psychological distress than those who reported 'good' and 'very good' sleep quality. 
Table 11. Predicting variables to psychological distress.

\begin{tabular}{|c|c|c|}
\hline \multirow[b]{2}{*}{ Variables } & \multicolumn{2}{|c|}{ Final Odds Ratio $(95 \% \mathrm{CI})$} \\
\hline & Normal vs. Distress & Normal vs. Severe or Extremely Severe Distress \\
\hline Gender & & 1 \\
\hline Male & - & $3.09(1.54,6.19)$ \\
\hline $\begin{array}{c}\text { Female } \\
\text { Age }\end{array}$ & & \\
\hline $\begin{array}{l}\text { Age } \\
50 \text { and above }\end{array}$ & 1 & 1 \\
\hline $21 \sim 49$ & $2.43(1.46,4.04)$ & $3.68(1.37,9.92)$ \\
\hline Do you have any conditions or diseases? & 1 & 1 \\
\hline No & $1.55(1.07,2.25)$ & $1.83(1.07,3.32)$ \\
\hline Yes $\ldots \ldots$ & & $1.83(1.07,3.32)$ \\
\hline Have tensions or even violent behavior increased in the & 1 & \\
\hline relationships with any of your family members? & $\begin{array}{c}1 \\
1\end{array}$ & 1 \\
\hline $\begin{array}{l}\text { No } \\
\text { Yes }\end{array}$ & $1.68(1.10,2.57)$ & $3.56(2.08,6.09)$ \\
\hline Have these tensions in your relationships with any of your & & \\
\hline family members? & 1 & \\
\hline No & $1.66(1.01,2.73)$ & - \\
\hline $\begin{array}{l}\text { Verbal or physical abuse } \\
\text { Comparing with the eating habits before the COVID-19 }\end{array}$ & & \\
\hline outbreak in Kuwait, what is your current amount of 'sweets & & \\
\hline $\begin{array}{l}\text { and snacks'? } \\
\text { J eat the same as before or less }\end{array}$ & $1.46(1.02,2.07)$ & - \\
\hline I eat more & & \\
\hline How many cigarettes do you usually smoke a day? (include & & \\
\hline electric cigarettes) & & 1 \\
\hline None & - & $3.06(1.47,6.36)$ \\
\hline Smoke every day & & \\
\hline How do you think about the quality of your sleep compared & & \\
\hline to what you had before the COVID-19 outbreak? & 1 & 1 \\
\hline Very good/good & $1.61(1.14,2.28)$ & $2.20(1.28,3.78)$ \\
\hline Poor/very poor & & \\
\hline
\end{tabular}

\section{Discussion}

Before the COVID-19 outbreak, Kuwait, similar to other countries, was attempting to achieve many targets from the Sustainable Development Goals to reduce mortality rates related to NCDs [29-33]. Since the pandemic, efforts towards achieving these goals have faced significant challenges and setbacks. Apart from being a physical health risk, COVID-19 has more wide-ranging impacts on mental health and well-being due to the disruptions caused to everyday life routines and the increased risks of detrimental behaviors, such as domestic abuse and violent behaviors within the family dynamic. The study's findings show a range of risk variables and the extent of the negative psychological impacts of the COVID-19 curfew on people living in Kuwait. These risk factors pose a significant threat to the public currently and have the potential to persist in the long run with severe public health ramifications. Therefore, opportunities for scaling up action addressing NCDs should be taken both immediately and as part of longer-term efforts to strengthen systems for health.

Findings from this study reveal the devastating effect of the pandemic on mental health and health behaviors. The effects of the pandemic and the associated interventions have led to myriads of emotional reactions resulting in experiencing symptoms of various mental health problems such as depression, anxiety, psychological distress, and stress. Moreover, unhealthy behaviors such as disrupted sleep patterns as well as reduced sleeping times and non-compliance with physical activity recommendations [34,35]. The findings from this study present evidence of the mental health impacts of the pandemic on adults living in Kuwait. Our results make it imperative to include mental health mitigations in any interventions or national plans to alleviate the effects of the COVID-19 pandemic in Kuwait. The need to continue monitoring mental health problems is necessary for developing an adequate response to emerging threats and incidents of deteriorating mental health, especially among those who were previously mentally healthy. This necessitates an urgent 
call for enhanced mental health surveillance to monitor individual and community mental health status during the various stages of the pandemic to respond timely and appropriately to support the changing mental health needs of the population.

The predictor variables identified in this study provide indicators for public health surveillance. Being single, divorced, or widowed, being female, living with chronic illhealth conditions and diseases, experiencing tensions or violent behaviors within the family, poor quality of sleep, smoking, and reduced physical activity predicted higher scores of depression, anxiety, stress, and psychological distress. Costanza et al. found that interpersonal and affective relationships with family, children, and grandchildren prevented suicide attempts and suicidal ideation through a protection mechanism [36]. These findings confirm that the absence of family, interpersonal relations, and social support from relationships due to being single, divorced, or widowed increases the risk of adverse psychological impacts. These variables have the potential of being used in forecasting the mental health status of individuals and should be taken into consideration when adapting or developing mental health interventions aimed at protecting and supporting individuals who are most vulnerable to experiencing impaired mental health status. Using predictions will be crucial in predicting an increase in prevalence and future psychological and psychiatric morbidities [37]. Specifically, targeting the modifiable variables among the predictors mentioned above presents crucial intervention points in the primary prevention of adverse mental health effects.

Our findings identify that females are at an increased risk of impaired mental health status during the pandemic compared to males. Despite depression being the only statistically significant difference between males and females, the latter show higher proportions of psychological distress (42.0\% vs. $37.8 \%)$, severe or extremely severe psychological distress (15.1\% vs. $9.1 \%)$, stress (18.3\% vs. $14.7 \%)$, and anxiety (14.5\% vs. $8.7 \%)$. Expectedly, mental health proportions match the risk factors that are related to mental ill-health. For instance, a larger proportion of females also reported increased tensions and violent behaviors, verbal and physical abuse, lack of sleep and rest, and adverse health symptoms [38,39]. According to Costanza et al., suicide attempts are significantly associated with interpersonal aggression [40]. The association of the pandemic-related restrictions with increased tensions, violent behaviors, and physical, verbal, and emotional abuse directed at females makes them more vulnerable to impulsivity and aggression-related suicidal behaviors and attempts [40].

The disproportionate spread of risk factors among females was observed by Guadagni, Umilta, and Iaria, who found that when compared to males, females reported lower quality of sleep and increased insomnia, anxiety, and depression, leading to higher burdens of mental health problems in females in Canada [41]. Disproportionate mental health effects of the pandemic among females were also reported in China [42,43], Brazil [44], Canada [45], and Spain [46]. The findings of this study corroborate other findings that have identified gender as a risk factor to psychosocial impacts of the pandemic. Other than gender, an analysis of the impact of the pandemic on psychiatric admissions in a Swiss hospital noted that a reduction in total emergency admissions was associated with living alone, among other factors [47]. Social isolation adds another layer of risk; in addition to unpartnered individuals facing an increased likelihood of stress and severe or extremely severe stress, they are also less likely to seek emergency psychiatric help. Therefore, females and those living alone are more vulnerable to the mental health effects of the pandemic than males and those living with partners. The existing interventions and prevention efforts currently being implemented in Kuwait should consider the differences in the risk and burden of mental health problems associated with the pandemic. Public health interventionists should use this knowledge to design targeted psychological interventions for populations deemed to be at higher risk.

The increased burden of psychological problems related to the pandemic and its restrictions point to an immediate need to adopt new technologies to increase the accessibility and quality of mental health services. Telepsychiatry and other forms of Mobile Health tech- 
nologies present practical solutions to improve mental health outcomes through enhanced access and quality services without requiring patients' physical presence $[48,49]$. Other advantages of telehealth include an increased effectiveness and cost-effectiveness [50,51]. According to Salum et al., the cost-effectiveness of such technologies presents a feasible strategy applicable to low- and middle-income countries to alleviate the adverse psychological and psychiatric instability associated with the pandemic [52]. While there are advantages to using technology to deliver therapeutic treatments, we must be careful not to replace human presence and interaction by relying heavily on technology [48], especially in light of our findings showing that disrupted social interactions and loss of connectedness are associated with adverse psychological effects.

Several limitations must be noted for this study. Firstly, the use of a cross-sectional design, and not longitudinal, impedes the certainty of the predictions. Hence, the predictions made in this study are, at best, hypothetical. Secondly, the study does not account for potentially confounding variables of psychological wellbeing such as body weight and religion in its measures. These variables are especially significant in the Kuwaiti context. However, this is the first study, to our knowledge, that explores the psychological and social impact of the COVID-19 curfew on people living in Kuwait during this period.

\section{Conclusions}

During this pandemic, the residents of Kuwait show negative psychological impacts attributable to the outbreak as well as the restrictions in place. The results show a need to focus on developing and implementing interventions that address the mental health needs of females to reduce the psychological distress, stress, anxiety, and depression that disproportionately affect them compared to males. These targeted interventions need to prioritize addressing behaviors such as increased tensions and violent behaviors, verbal and physical abuse, lack of sleep and rest, physical inactivity, and adverse health symptoms shown to predict mental health problems within the population. Mental health problems already affect many individuals living in Kuwait, and there is a possibility that these effects might persist long after the pandemic. More than ever, Kuwait needs to institute mental health interventions that target identified needs and address health inequities through improving health behaviors and social support, enhancing healthier coping mechanisms with COVID-19-related stress, establishing systems for family counseling, and providing accessible and acceptable facilities that encourage healthy lifestyles for the most vulnerable individuals. The success of such interventions will alleviate the current burden and prevent the worsening of the mental health situation among individuals impacted by the pandemic and support prevention and efforts for potential future pandemics.

Author Contributions: Conceptualization, A.S.; formal analysis, A.S. and S.C.; funding acquisition, A.S. and A.K.T.; investigation, A.S.; methodology, A.S. and S.C.; project administration, A.S.; validation, A.S., F.A.-G., K.O.S., and A.K.T.; visualization, A.S. and S.C.; writing-original draft, A.S.; writing-review and editing, A.S., F.A.-G., K.O.S., and A.K.T. All authors have read and agreed to the published version of the manuscript.

Funding: This research was funded by the UNDP Kuwait and the APC was funded by the Kuwait Institute for Scientific Research (KISR). The findings reported herein are solely the responsibility of the authors.

Institutional Review Board Statement: The study was conducted according to the guidelines of the Declaration of Helsinki and approved by the Research Ethics Review Committee of the Kuwait Ministry of Health (Research number 2020/1487 and date of approval 8 June 2020).

Informed Consent Statement: Informed consent was obtained from all subjects involved in the study.

Data Availability Statement: The raw data supporting the conclusions of this article will be made available by the authors without undue reservation.

Conflicts of Interest: The authors declare no conflict of interest. 


\section{References}

1. World Health Organization. Novel Coronavirus (2019-nCoV): Situation Report-1; World Health Organization: Geneva, Switzerland, 2020.

2. World Health Organization. WHO Timeline-COVID-19. Available online: https://www.who.int/news/item/27-04-2020-whotimeline---covid-19 (accessed on 13 May 2021).

3. The Central Agency for Information. Technology COVID 19 Updates: Sate of Kuwait-Live. Available online: https:/ / corona.e. gov.kw/En/ (accessed on 30 April 2021).

4. Salman, A.; Sigodo, K.O.; Al-Ghadban, F.; Al-Lahou, B.; Alnashmi, M.; Hermassi, S.; Chun, S. Effects of COVID-19 Lockdown on Physical Activity and Dietary Behaviors in Kuwait: A Cross-Sectional Study. Nutrients 2021, 13, 2252. [CrossRef]

5. Zhou, F.; Yu, T.; Du, R.; Fan, G.; Liu, Y.; Liu, Z.; Xiang, J.; Wang, Y.; Song, B.; Gu, X.; et al. Clinical course and risk factors for mortality of adult inpatients with COVID-19 in Wuhan, China: A retrospective cohort study. Lancet 2020, 395, 1054-1062. [CrossRef]

6. Choi, E.P.H.; Hui, B.P.H.; Wan, E.Y.F. Depression and Anxiety in Hong Kong during COVID-19. Int. J. Environ. Res. Public Health 2020, 17, 3740. [CrossRef]

7. Hyland, P.; Shevlin, M.; McBride, O.; Murphy, J.; Karatzias, T.; Bentall, R.P.; Martinez, A.; Vallières, F. Anxiety and depression in the Republic of Ireland during the COVID-19 pandemic. Acta Psychiatr. Scand. 2020, 142, 249-256. [CrossRef]

8. Brown, S.M.; Doom, J.R.; Lechuga-Peña, S.; Watamura, S.E.; Koppels, T. Stress and parenting during the global COVID-19 pandemic. Child Abus. Negl. J. 2020, 110, 104699. [CrossRef] [PubMed]

9. Tull, M.T.; Edmonds, K.A.; Scamaldo, K.M.; Richmond, J.R.; Rose, J.P.; Gratz, K.L. Psychological Outcomes Associated with Stay-at-Home Orders and the Perceived Impact of COVID-19 on Daily Life. Psychiatry Res. 2020, 289, 113098. [CrossRef] [PubMed]

10. Alasousi, L.; al Hammouri, S.; Al-abdulhadi, S. al Anxiety and media exposure during COVID-19 outbreak in Kuwait. medRxiv 2020, 24, 745 .

11. Sifat, R.I. Impact of the COVID-19 pandemic on domestic violence in Bangladesh. Asian J. Psychiatry J. 2020, 53, 102393. [CrossRef] [PubMed]

12. Brailovskaia, J.; Margraf, J. Predicting adaptive and maladaptive responses to the Coronavirus (COVID-19) outbreak: A prospective longitudinal study. Int. J. Clin. Heal. Psychol. 2020, 20, 183-191. [CrossRef]

13. Abbas, J.; Wang, D.; Su, Z.; Ziapour, A. The Role of Social Media in the Advent of COVID-19 Pandemic: Crisis Management, Mental Health Challenges and Implications. Risk Manag. Healthc. Policy 2021, 14, 1917-1932. [CrossRef] [PubMed]

14. Sukeri, S.; Zahiruddin, W.M.; Shafei, M.N.; Hamat, R.A.; Osman, M.; Jamaluddin, T.Z.M.T.; Daud, A.B. Perceived severity and susceptibility towards leptospirosis infection in Malaysia. Int. J. Environ. Res. Public Health 2020, 17, 6362. [CrossRef] [PubMed]

15. World Health Organization Infodemic. Available online: https://www.who.int/health-topics/infodemic\#tab=tab_1 (accessed on 12 May 2021).

16. Young, M.E.; Norman, G.R.; Humphreys, K.R. Medicine in the Popular Press: The Influence of the Media on Perceptions of Disease. PLoS ONE 2008, 3, e3552. [CrossRef]

17. Chan, E.Y.Y.; Huang, Z.; Lo, E.S.K.; Hung, K.K.C.; Wong, E.L.Y.; Wong, S.Y.S. Sociodemographic predictors of health risk perception, attitude and behavior practices associated with health-emergency disaster risk management for biological hazards: The case of COVID-19 pandemic in Hong Kong, SAR China. Int. J. Environ. Res. Public Health 2020, 17, 3869. [CrossRef]

18. Rosenstock, I.M. The Health Belief Model and Preventive Health Behavior. Health Educ. Monogr. 1974, 2, 354-386. [CrossRef]

19. Janz, N.K.; Becker, M.H. The Health Belief Model: A Decade Later. Heal. Educ. Behav. 1984, 11, 1-47. [CrossRef] [PubMed]

20. Petrie, K.J.; Weinman, J. Why illness perceptions matter. Clin. Med. Northfield. 2006, 6, 536-539. [CrossRef]

21. Kim, C.W.; Song, H.R. Structural Relationships among Public's Risk Characteristics, Trust, Risk Perception and Preventive Behavioral Intention-The Case of MERS in Korea. Crisisonomy 2017, 13, 85-95. [CrossRef]

22. Rosenstock, I.M.; Strecher, V.J.; Becker, M.H. Social Learning Theory and the Health Belief Model. Health Educ. Q. 1988, 15, 175-183. [CrossRef] [PubMed]

23. World Health Organization. Survey Tool and Guidance: Rapid, Simple, Flexible Behavioral Insights on COVID-19; WHO Regional Office for Europe: Copenhagen, Denmark, 2020.

24. United Nations. Policy Brief: COVID-19 and the Need for Action on Mental Health; United Nations: New York, NY, USA, 2020.

25. Shahnazi, H.; Ahmadi-Livani, M.; Pahlavanzadeh, B.; Rajabi, A.; Hamrah, M.S.; Charkazi, A. Assessing preventive health behaviors from COVID-19: A cross sectional study with health belief model in Golestan Province, Northern of Iran. Infect. Dis. Poverty 2020, 9, 157. [CrossRef]

26. Yusoff, M.S.B. Psychometric properties of the depression anxiety stress scale in a sample of medical degree applicants. Int. Med. J. 2013, 20, 295-300.

27. The International Physical Activity Questionnaire Guidelines for Data Processing and Analysis of the International Physical Activity (IPAQ). Available online: http:/ / www.ipaq.ki.se/ (accessed on 30 April 2021).

28. American Association for Public Opinion Research the Code of Professional Ethics and Practices. Available online: https: //www.aapor.org/Standards-Ethics/AAPOR-Code-of-Ethics.aspx (accessed on 21 June 2020).

29. Salman, A.; Tolma, E.; Chun, S.; Sigodo, K.O.; Al-Hunayan, A. Health Promotion Programs to Reduce Noncommunicable Diseases: A Call for Action in Kuwait. Healthcare 2020, 8, 251. [CrossRef] 
30. Salman, A.; Fakhraldeen, S.A.; Chun, S.; Jamil, K.; Gasana, J.; Al-Hunayan, A. Enhancing Research and Development in the Health Sciences as a Strategy to Establish a Knowledge-Based Economy in the State of Kuwait: A Call for Action. Healthcare 2020, 8, 264. [CrossRef] [PubMed]

31. Chun, S.; Salman, A. Policy Paper for the Health Pillar: Overview of Gaps, Challenges, and Way Forward in Kuwait National Development Plan 2015-2020; Kuwait Public Policy Center, General Secretariat of the Supreme Council for Planning and Development: Kuwait City, Kuwait, 2019.

32. Chun, S.; Salman, A. White Paper for the Health Pillar National Health Policy Framework: Ensuring Healthy Lives and Wellbeing; Kuwait Public Policy Center, General Secretariat of the Supreme Council for Planning and Development: Kuwait City, Kuwait, 2019.

33. Chun, S.; Salman, A. Research Agenda for the Health Pillar; Kuwait Public Policy Center, General Secretariat of the Supreme Council for Planning and Development: Kuwait City, Kuwait, 2019.

34. Pfefferbaum, B.; North, C.S. Mental Health and the Covid-19 Pandemic. N. Engl. J. Med. 2020, 383, 510-512. [CrossRef]

35. Hermassi, S.; Sellami, M.; Salman, A.; Al-Mohannadi, A.S.; Bouhafs, E.G.; Hayes, L.D.; Schwesig, R. Effects of COVID-19 Lockdown on Physical Activity, Sedentary Behavior, and Satisfaction with Life in Qatar: A Preliminary Study. Int. J. Environ. Res. Public Health 2021, 18, 3093. [CrossRef]

36. Costanza, A.; Amerio, A.; Odone, A.; Baertschi, M.; Richard-Lepouriel, H.; Weber, K.; Di Marco, S.; Prelati, M.; Aguglia, A.; Escelsior, A.; et al. Suicide prevention from a public health perspective. What makes life meaningful? The opinion of some suicidal patients. Acta Biomed 2020, 91, 128-134. [PubMed]

37. Cullen, W.; Gulati, G.; Kelly, B.D. Mental health in the COVID-19 pandemic. QJM An. Int. J. Med. 2020, 113, 311-312. [CrossRef]

38. Sediri, S.; Zgueb, Y.; Ouanes, S.; Ouali, U.; Bourgou, S.; Jomli, R.; Nacef, F. Women's mental health: Acute impact of COVID-19 pandemic on domestic violence. Arch. Womens. Ment. Health 2020, 23, 749-756. [CrossRef] [PubMed]

39. Thibaut, F.; van Wijngaarden-Cremers, P.J.M. Women's Mental Health in the Time of Covid-19 Pandemic. Front. Glob. Women Heal. 2020, 1, 588372. [CrossRef]

40. Costanza, A.; Rothen, S.; Achab, S.; Thorens, G.; Baertschi, M.; Weber, K.; Canuto, A.; Richard-Lepouriel, H.; Perroud, N.; Zullino, D. Impulsivity and Impulsivity-Related Endophenotypes in Suicidal Patients with Substance Use Disorders: An Exploratory Study. Int. J. Ment. Health Addict. 2020. [CrossRef]

41. Guadagni, V.; Umilta', A.; Iaria, G. Sleep Quality, Empathy, and Mood During the Isolation Period of the COVID-19 Pandemic in the Canadian Population: Females and Women Suffered the Most. Front. Glob. Women Heal. 2020, 1, 585938. [CrossRef]

42. Liu, S.; Yang, L.; Zhang, C.; Xu, Y.; Cai, L.; Ma, S.; Wang, Y.; Cai, Z.; Du, H.; Li, R.; et al. Gender differences in mental health problems of healthcare workers during the coronavirus disease 2019 outbreak. J. Psychiatr. Res. 2021, 137, 393-400. [CrossRef]

43. Yan, S.; Xu, R.; Stratton, T.D.; Kavcic, V.; Luo, D.; Hou, F.; Bi, F.; Jiao, R.; Song, K.; Jiang, Y. Sex differences and psychological stress: Responses to the COVID-19 pandemic in China. BMC Public Health 2021, 21, 79. [CrossRef] [PubMed]

44. Ferreira, H.G. Gender Differences in Mental Health and Beliefs about Covid-19 among Elderly Internet Users. Paidéia 2021, 31, e3110. [CrossRef]

45. Prowse, R.; Sherratt, F.; Abizaid, A.; Gabrys, R.L.; Hellemans, K.G.C.; Patterson, Z.R.; McQuaid, R.J. Coping With the COVID-19 Pandemic: Examining Gender Differences in Stress and Mental Health Among University Students. Front. Psychiatry 2021, 12, 650759. [CrossRef]

46. García-Fernández, L.; Romero-Ferreiro, V.; Padilla, S.; David López-Roldán, P.; Monzó-García, M.; Rodriguez-Jimenez, R. Gender differences in emotional response to the COVID-19 outbreak in Spain. Brain Behav. 2021, 11, e01934. [CrossRef] [PubMed]

47. Ambrosetti, J.; Macheret, L.; Folliet, A.; Wullschleger, A.; Amerio, A.; Aguglia, A.; Serafini, G.; Prada, P.; Kaiser, S.; Bondolfi, G.; et al. Impact of the COVID-19 Pandemic on Psychiatric Admissions to a Large Swiss Emergency Department: An Observational Study. Int. J. Environ. Res. Public Health 2021, 18, 1174. [CrossRef] [PubMed]

48. Bhugra, D.; Tasman, A.; Pathare, S.; Priebe, S.; Smith, S.; Torous, J.; Arbuckle, M.R.; Langford, A.; Alarcón, R.D.; Chiu, H.F.K.; et al. The WPA-Lancet Psychiatry Commission on the Future of Psychiatry. The Lancet Psychiatry 2017, 4, 775-818. [CrossRef]

49. Costanza, A.; Ambrosetti, J.; Wyss, K.; Bondolfi, G.; Sarasin, F.; Khan, R. Preventing suicide in emergencies: From “Interpersonal Suicide Theory" to connectedness. Rev. Med. Suisse 2018, 4, 335-338.

50. Deslich, S.; Stec, B.; Tomblin, S.; Coustasse, A. Telepsychiatry in the 21st century: Transforming healthcare with technology. Perspect. Heal. Inf. Manag. 2013, 10, 1. Available online: https://www.researchgate.net/publication/249967520_Telepsychiatry_ in_the_21st_Century_Transforming_Healthcare_with_Technology (accessed on 21 June 2020).

51. Costanza, A.; Mazzola, V.; Radomska, M.; Amerio, A.; Aguglia, A.; Prada, P.; Bondolfi, G.; Sarasin, F.; Ambrosetti, J. Who Consults an Adult Psychiatric Emergency Department? Pertinence of Admissions and Opportunities for Telepsychiatry. Med. B Aires 2020, 56, 295. [CrossRef]

52. Salum, G.A.; Rehmenklau, J.F.; Csordas, M.C.; Pereira, F.P.; Castan, J.U.; Ferreira, A.B.; Delgado, V.B.; de Bolzan, L.M.; de Lima, M.A.; Blauth, J.H.; et al. Supporting people with severe mental health conditions during the COVID-19 pandemic: Considerations for low- and middle-income countries using telehealth case management. Braz. J. Psychiatry 2020, 42, 451. [CrossRef] [PubMed] 